\title{
System architecture to bring smart personal protective equipment wearables and sensors to transform safety at work in the underground mining industry
}

The Mining-Geology-Petroleum Engineering Bulletin UDC: 622.8

DOI: $10.17794 / \operatorname{rgn} .2019 .1 .4$

Preliminary communication

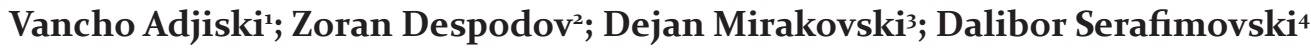 \\ ${ }^{1}$ Faculty of Natural and Technical Sciences, Mining Engineering, "Goce Delchev" University, P.O. Box 201, 2000 Shtip, Macedonia \\ ${ }^{2}$ Faculty of Natural and Technical Sciences, Mining Engineering, "Goce Delchev" University, P.O. Box 201, 2000 Shtip, Macedonia \\ ${ }^{3}$ Faculty of Natural and Technical Sciences, Mining Engineering, "Goce Delchev" University, P.O. Box 201, 2000 Shtip, Macedonia \\ ${ }^{4}$ Faculty of Computer Science, “Goce Delchev" University, P.O. Box 201, 2000 Shtip, Macedonia
}

\begin{abstract}
As safety at work has become a number one priority in every industry, it is no wonder that new technology and ideas are being tested to improve safety in a variety of workplaces, including, surface and underground mining, construction sites, power plants, factories, etc. Sensor technologies embedded in personal protective equipment (PPE), can be employed to monitor workers' health, exposure to harmful elements, their proximity to danger zones, etc. This technology connected to smartphones and smartwatches can also heighten workers' awareness by collecting data on the workplace itself, detecting environmental and health hazards. In this paper, we will present a prototype system that can be employed in underground mining which uses sensors attached to regular PPE clothing, including hard hats and safety glasses which are connected to smartphones and smartwatches via energy-efficient Bluetooth sensors, to provide real-time safety situation awareness and predict health and safety incidents before they occur.
\end{abstract}

Keywords:

underground mining, PPE, IoT, sensors, safety at work.

\section{Introduction}

In most industries, using the term "smart" means increasing efficiency and effectiveness, but in the mining industry there is a vital additional ingredient, and that is human safety. The mine of the future must do things in a smarter way in order to reduce costs, lower emissions and increase productivity, while ensuring safety is paramount (Hu et al., 2013; Jiang et al., 2017). There is a need for a personal safety system that monitors and sends alerts to smartphones for the safety of people on site, provides real-time data, location-specific alerts, health monitoring, improves communication, etc. (Barro-Torres et al., 2012).

The system presented in this paper works by making a miner's personal protective equipment (PPE) "smart", with embedded sensors on all their PPE which includes: safety glasses, hard hats, miners' clothing, and also by wearing smart technology gadgets like smartphones and smartwatches that can monitor and inform mine personnel of potential safety hazards (see Figure 1). The most obvious way technology improves safety is through PPE, where smart technology upgrades make what is already standard to all the industries do an even better job

Corresponding author: Vancho Adjiski

vanco.adziski@ugd.edu.mk
(Podgórski et al., 2017). This smart technology embedded in a PPE can provide safety alerts to workers in the field, remind them of specific safety procedures, and even enable an injured worker to reach out for help automatically (Amft and Lukowicz, 2009; Burchard et al., 2001).

The term "Internet of Things" (IoT) is a new trend where a number of embedded devices and sensors employ communication services offered by different Internet protocols (Atzori et al. 2010). Many of these devices (smart objects) are not directly operated by humans, but exist as components in the environment. IoT technology offers the possibility to transform the underground mining industry by providing and increasing the availability of information throughout the working cycle using networked sensors.

The mining sector is in the process of a technological revolution with the implementation of smart technologies that can boost productivity and improve safety. The implementation of smart technologies has the potential to address those challenges, however, higher investment costs can pose challenges to its widespread adoption ( $\mathbf{H u}$ et al., 2013; Jiang et al., 2017; Qiupinga et al., 2011).

In this paper, we will present a prototype system that uses available smart technology implemented so as to get the highest efficiency from the system for the lowest implementation price. 


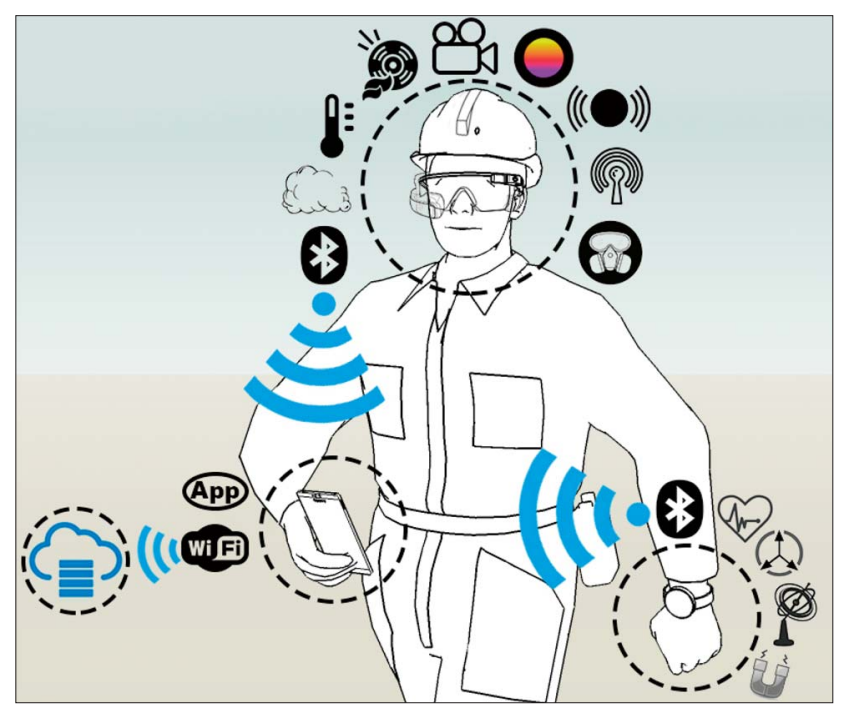

Figure 1: Prototype system with sensors embedded in PPE interconnected with smart technology

Combining smart technology and underground mining could lead to next-generation mines, by means of digitalization this system takes advantages of active sensing, remote signal, data processing, communication, and improves the efficiency and safety of the mining process.

\section{Potential of combining PPE, sensors and the IoT}

As devices become embedded with all kind of sensors and gain the ability to communicate between themselves, they are becoming tools for understanding complexity and responding to it swiftly. The IoT is a network of physical objects that contain embedded technology such as electronics, software, sensors, actuators, and network connectivity, which enables these objects to collect and exchange data to serve a meaningful purpose (Miorandi et al., 2012). We can use this new technology to perform complex tasks that require a high degree of intelligence and enter a new world where almost all the devices that we use are connected to a network.

More and more companies each year adopt sensors and connectivity to provide better safety and long-term cost savings through the active prevention of health issues and tragic situations. This new technology trend has a good and solid foundation for implementation in the area of PPE, where its primary purpose, besides compliance to regulations, will also be to increase protection by lowering the risk of and even preventing workplace injuries (Mukhopadhyay, 2015).

IoT can trigger innovation in the field of PPE where companies can produce wearable technologies that improve work performance and reduce error, along with products that send this information to systems that can monitor and improve the work environment (Rooney et al., 2006). The new IoT development platforms enable companies of all sizes and resources to take advantage of smart technology and plan the right concept for their needs, choosing exactly which hardware and smart behaviors they want in their environment.

Many industries are already realizing the benefits of smart technology for data-driven decision-making that can enable end-users to collect information about their own use (Zaslavsky et al., 2012). The possibilities for smart technology, sensors and PPE in the underground mining industry are tremendous.

Today, it is easy to pinpoint the reasons for the rapid rise in the adoption of smart technology, because electronics and hardware prices continue to fall, so the costs of embedded sensors and connectivity no longer deter companies from adopting this smart technology.

Opposite to the Internet world, the underground mining industry usually belongs to resource challenged environments where energy, computing resources and data throughput are scarce. Connectivity solutions, including Wi-Fi, Bluetooth, Zigbee and mobile networks are capable of supporting large volumes of IoT connectivity at little incremental cost for the consumers. Smart sensors and component devices, in combination with connectivity solutions and data storage, enable PPE to offer better safety and health protection (Perera et al., 2014). IoT platforms are able to merge and create strong systems that provide many solutions for developing smart PPE products. With these solutions PPE manufacturers can take a smart concept from the initial idea to prototype creation.

\section{Methods}

\subsection{Methodology for system integration and PPT assembly}

Most of the IoT solutions are small subnets of interconnected objects and processes. To improve this interconnectivity, in this paper we will present an architecture that ensures interoperability of the whole system. Figure 2 shows a five-layer architecture introduced in

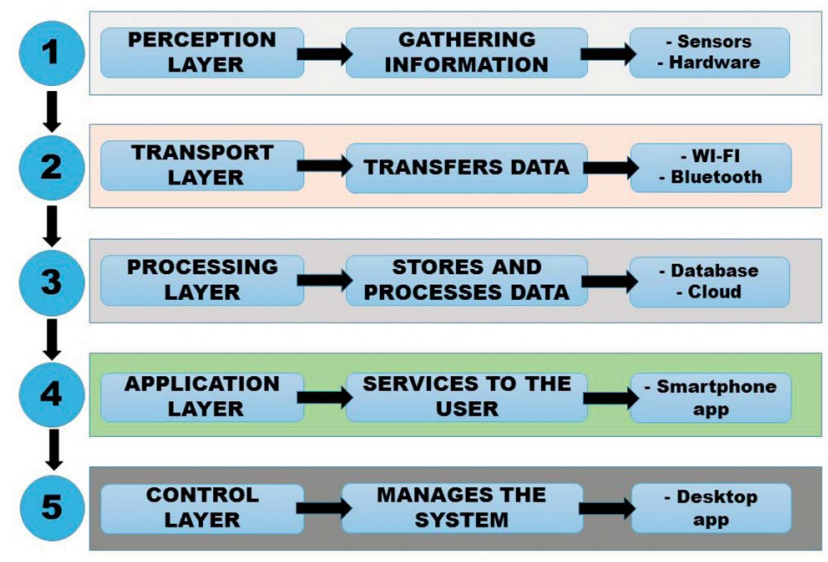

Figure 2: Methodology of integration that enables interoperability in the whole system 
this research that has been able to connect and manage all of its components.

The perception layer is the foundation layer, which has all the necessary sensors for gathering information about the mining environment. It senses some physical parameters in the environment and also identifies other smart objects.

The transport layer transfers the collected sensor data from the perception layer to the smartphone via Bluetooth on a local smartphone database and then through Wi-Fi to the processing layer.

The processing layer stores, processes and analyses huge amounts of data that come from the transport layer. The processing layer can provide a set of services to the lower layers with the help of databases and cloud computing modules. The data collected from the sensors is primarily stored in local SQLite databases and is actively synchronized to a server when an internet connection is available to the smartphone device. The proposed model includes statistical processing of health data with the help of Microsoft HealthVault and Apple HealthKit.

The application layer contains a smartphone application that is responsible for delivering specific services to the user. For the needs of the proposed model a multiplatform smartphone application is used that is the main base station for all the incoming data. The smartphone application communicates with a local server to which it automatically sends data at a time when an internet connection is available.

The control layer manages the whole system, including the smartphone application and users' profiles. The system is managed with the help of a multiplatform oriented desktop application. The desktop application consists of three main sections:

- a section for database administration,

- a section for monitoring data from the smartphone application,

- a section for administration of user profiles.

In this paper, a prototype model of PPE will also be presented which outlines the developments in smart and wearable technologies with the capabilities of improving worker productivity, better safety and active prevention of accidents. Sensors are essential components of these smart and wearable technologies integrated in PPE because they present one of the most important aspects of the IoT and that is context awareness (Makris et al.,

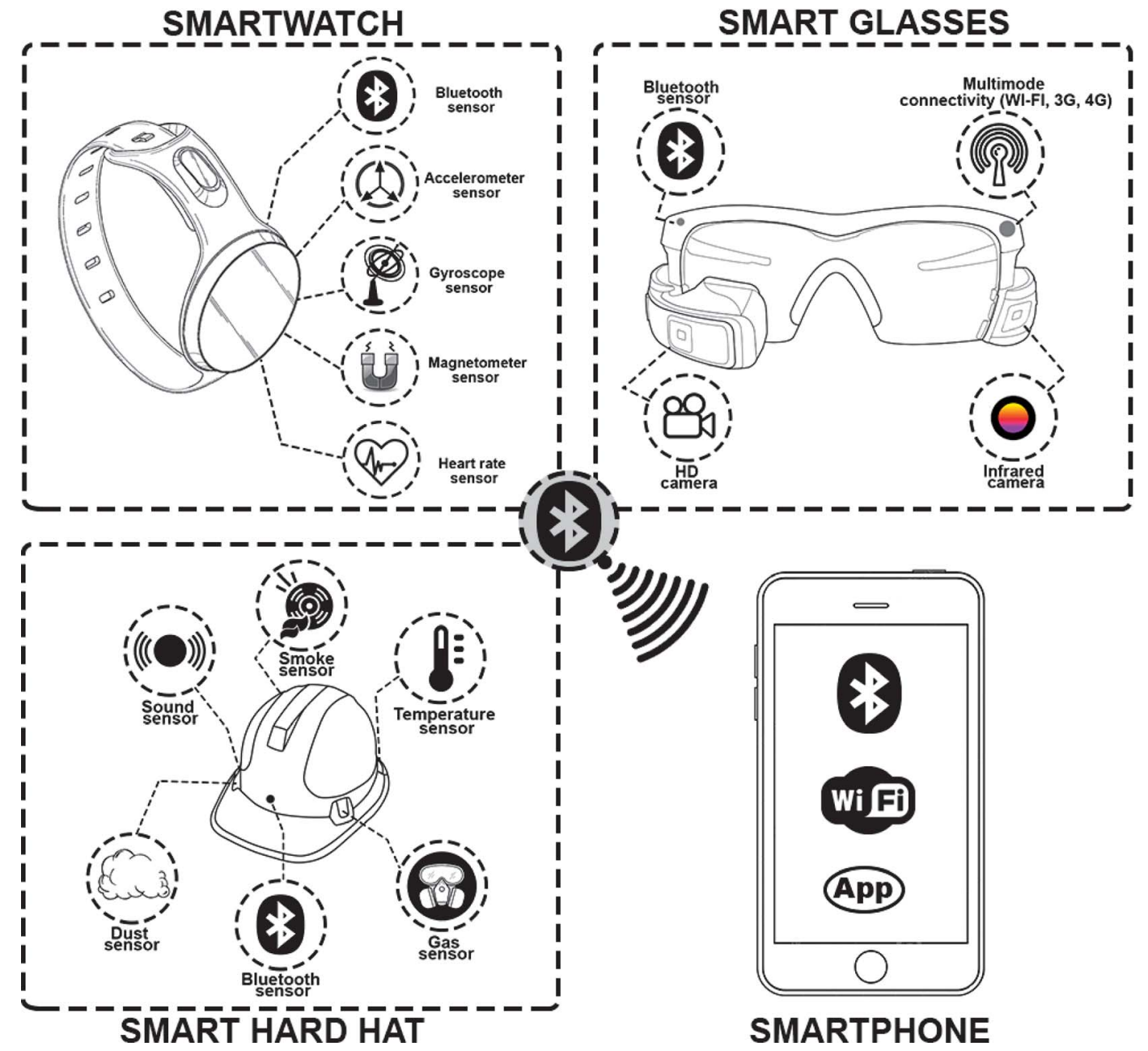

Figure 3: Smart technology and sensor upgrades in PPE 
2013; Witt et al., 2013). These sensors are mostly small in size, they consume less power and are low cost. Figure 3, presents the prototype model of PPE with integrated sensors and smart technology which are interconnected with the five-layer architecture shown in Figure 2.

A smartphone application uses the sensors' data to produce meaningful results to the end user. The sensors that are inside this prototype model of PPE with the interconnection of smart technology are as follows (Bertino et al., 2015; Guidoa et al., 2012; Mourcou et al., 2015; Su et al., 2014):

1. Bluetooth Low Energy, also known as "Bluetooth Smart," is a wireless personal area network technology that enables short-burst wireless connections and is designed to provide considerably reduced power consumption while connecting device products.

2. A gas sensor is a device that detects or quantifies the presence or the concentration of gases in a specific volume of air. This type of equipment is used to detect oxygen depletion and combustible, flammable and toxic gases.

3. A dust sensor is designed to sense dust particles which can give a good indication of the air quality in an environment by measuring dust concentration.

4. A sound sensor can detect the damaging noise intensity in the environment and can provide helpful information and address noise challenges in the workplace.

5. A smoke sensor is a device that senses smoke, typically as an indicator of fire. Smoke sensors will detect fires more rapidly than temperature sensors and this early warning sensor is critical to save lives and minimize property loss.

6. A temperature sensor measures the amount of heat energy that is generated by an object or system, allowing us to detect any physical change in that temperature. This risk arises from specific external factors such as a harsh operating environment, and, by detecting when overheating occurs, we can take preventative actions.

7. An accelerometer sensor measures the motion and acceleration of an object and typically measures changes in velocity of the object in three dimensions. The data captured by the accelerometer sensor can be used to detect physical activities of the user such as running and walking.

8. Gyroscope sensors are devices that sense angular velocity and when rotating, the orientation of this axis is unaffected by tilting or rotation of the mounting. Because of this, gyroscopes are useful for measuring or maintaining orientation.

9. A magnetometer sensor detects magnetic fields or the direction, strength, and the relative change of a magnetic field at a particular location and this can be used as a digital compass and in applications to detect the presence of metals.
10. A heart rate sensor measures the heart rate in real time or records the heart rate for later study. Knowing the heart rate can be useful because it helps to determine whether the work activity could present physical complications.

11. An HD camera can provide video of a higher resolution to visualize the underground mining surroundings.

12. Infrared cameras are very robust towards environmental influence and can be used to monitor thermal performance, and also identify and evaluate the relative severity of heat-related problems. Infrared cameras can be used as an imaging method for rough environments such as the mining industry.

\section{Results and discussion}

\subsection{Practical applications in underground mining}

The underground mining industry faces big challenges brought by a long history of accidents, technological immaturity and closed systems. Now they can rely on what innovative approaches can provide with new ways to increase asset efficiency, ensure worker safety, decrease costs, increase productivity, etc. Underground mining is the perfect test bed for innovation because so far, it has lived on nothing else but small incremental changes in the implementation of smart technology and it also provides challenges where both economic and quality of life issues can be addressed simultaneously (Bhattacharjee et al., 2012).

The safety of workers should be the number one priority in every underground mine but the manner in which the industry currently monitors the quality of air on every underground work location and the health of every worker is outdated compared to the modern world. In many underground mines today, a person is sent to go through the mine, and document the status of oxygen levels and dangerous gases, manually read sensors and then record this data on physical boards at a central location. This old methodology does not allow for any automated response to changes in conditions and real-time monitoring, and it also requires a person to be placed in a potentially dangerous situation. While many underground mines may have stationary placed sensors, many of them are not connected to intelligent networks and systems that could deliver safer real-time recommendations.

Innovation starts with an ambitious idea and then shapes it into something real with the capacity to address significant problems. Those initial ideas may spark an innovation opportunity and fuel early stage exploration through prototypes.

With this prototype system specially adapted for the needs of the underground mining industry that uses sensors attached to regular PPE clothing, including hard 


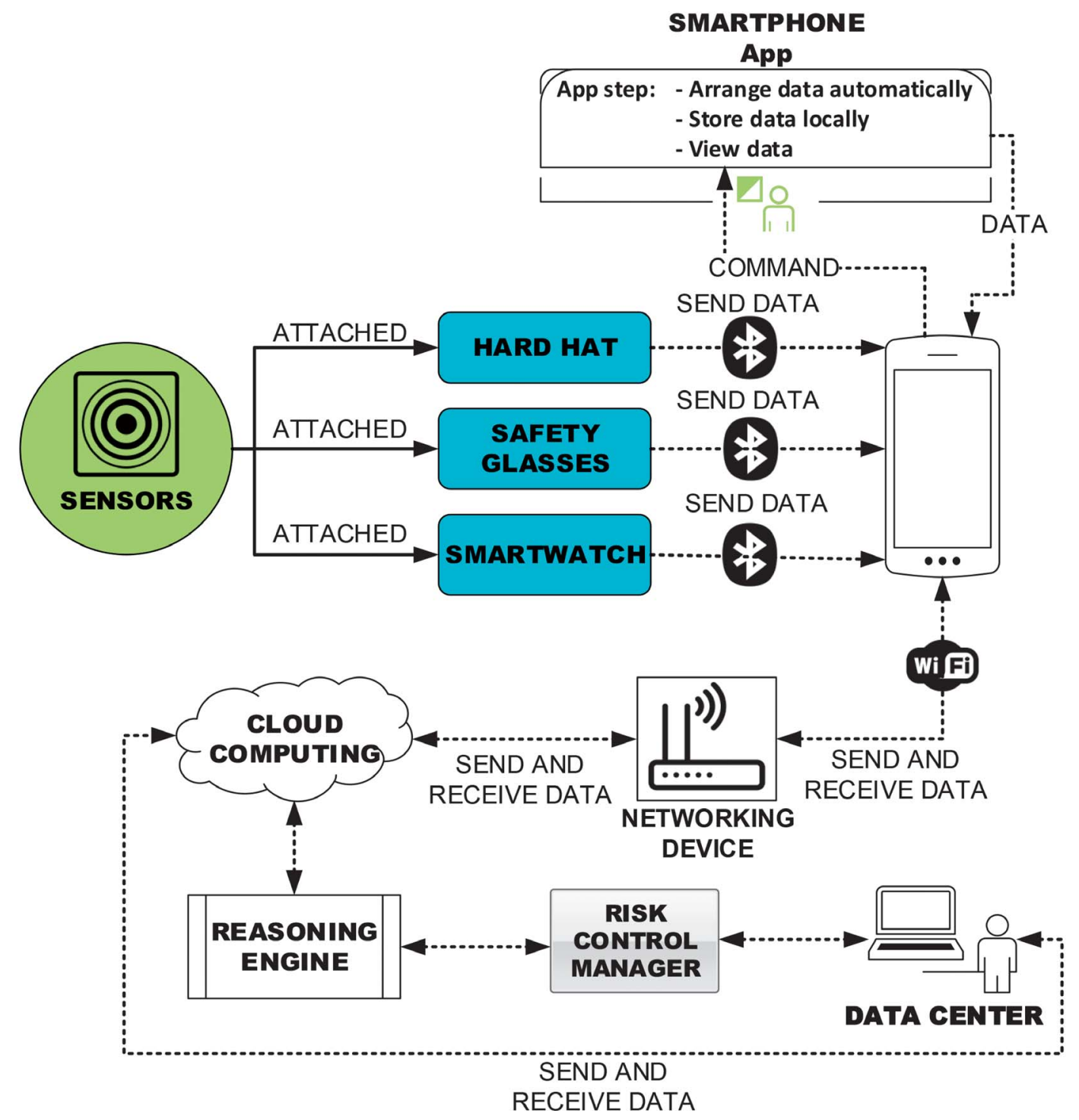

Figure 4: Framework of the smart PPE wearables, sensors and the cloud computing system

hats and safety glasses which are connected with smartphone and smartwatch via energy-efficient Bluetooth sensors, real-time safety situation-awareness could be provided and health and safety incidents could be predicted before they occur.

The focus of this paper is on architecting an approach to the problem that supports the initial divergence of ideas to a deployable model for pilot testing. The prototype system presented in this paper demonstrates important communication capabilities between the working environment, workers and cloud computing (see Figure 4).

In this system, sensors are attached to PPE to gather data points in real-time about gas levels and exposure to other harmful elements, whose data is then sent through Bluetooth to the local smartphone database. With the help of a specially programmed application for this need, this data is arranged automatically for the user and then when an internet connection is available, it is sent via Wi-Fi to the networking device that enables the data to be stored locally or in the cloud.
The stored data in the cloud that contains historical and current data collected from all sensors assigned to various smart objects, is then sent to a reasoning engine, i.e., a module responsible for context-based reasoning with regard to current and possible future situations, and also for performing a real-time assessment of risks for individual workers (Bettini et al., 2010; Edwards et al., 2000; Forsyth et al.,2012). This data is then sent to the module for risk control manager, which analyses the resources available for controlling the risks and selects appropriate protection and preventive measures. From there, this data is

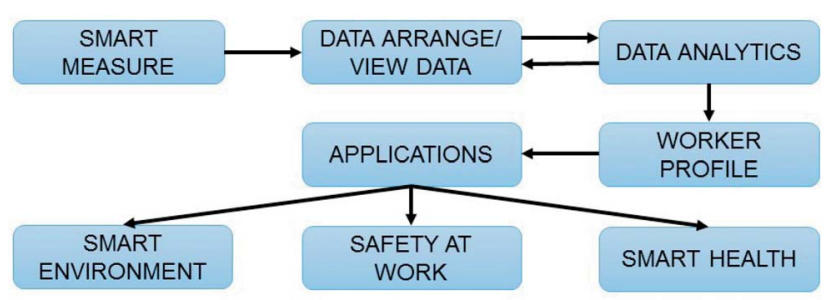

Figure 5: Applications of the proposed system 


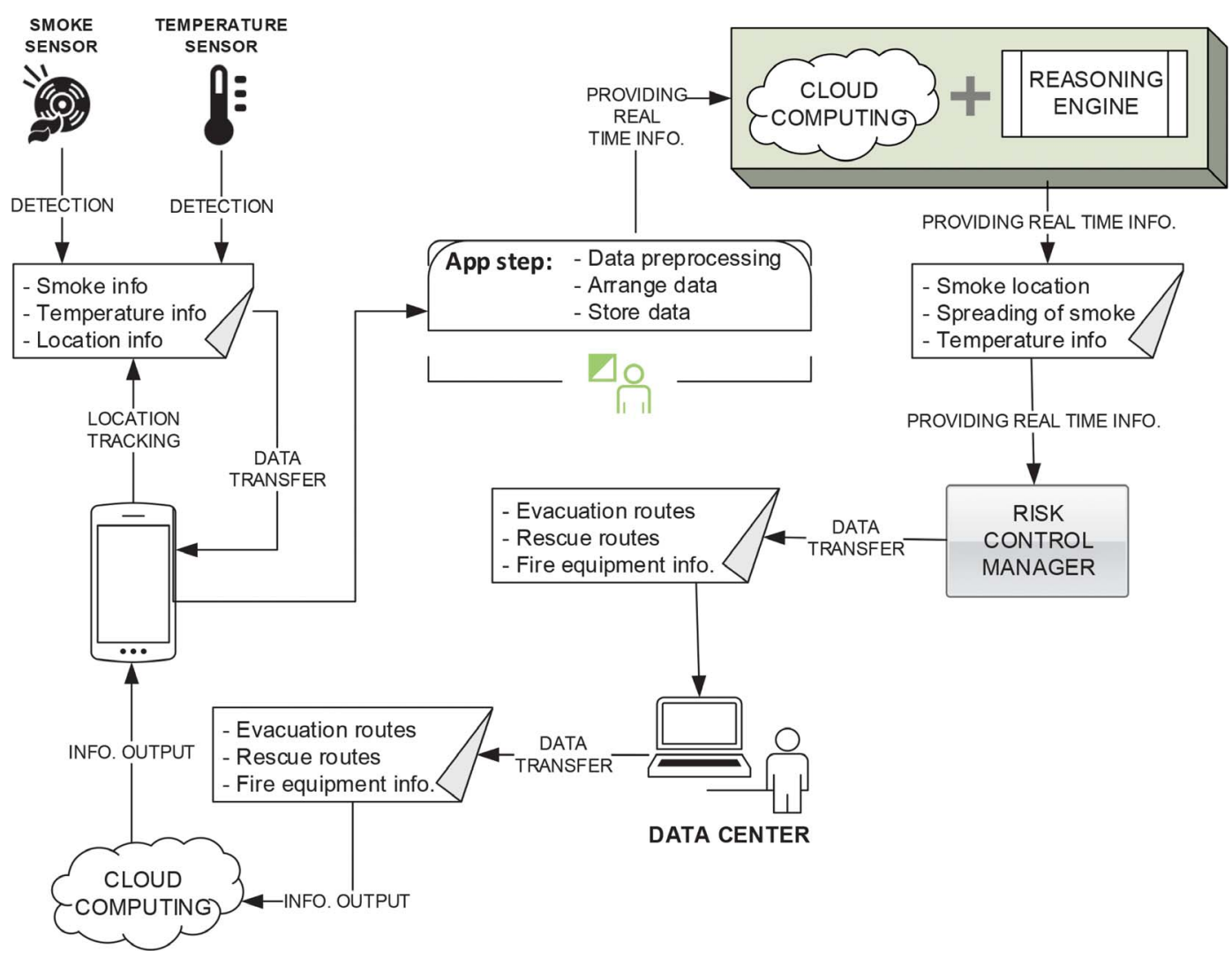

Figure 6: Modelling of example scenario

then sent to the data centre where it is analysed and viewed in dashboards on computers by human operators who can then send information to the smartphone of the appropriate user with the help of a gateway that enables information to travel back through the network. Stored data on the cloud enables the generation of analytics and visualizations of environmental and health hazards conditions in the mine. Figure 5 shows some of the possible application fields for this system.

\subsection{Modelling of example scenario}

Based on the discussions in the previous sections, this research proposes a prototype of a "smart" product attached to regular PPE clothing that collects data from sensors and then communicates that data to other IoT devices to provide real-time safety situation-awareness. Figure 6 shows an example scenario where some of the possibilities of the proposed system can be seen. With the help of the attached sensors on PPE for smoke and temperature the perception layer detects environmental information with signs of fire. This data is then sent to the user's smartphone from where the data together with the location info from the smartphone is pre-processed in the application. The automatically stored and arranged data forms the smartphone application and through Wi-Fi it sends real time info to cloud computing with a reasoning engine and risk control manager modules performing a real-time assessment of risks and appropriate protection measures are sent to the data centre for addi- tional analysis and evacuation route decisions. Moreover, the example scenario shows that this system provides effective real-time and two-way fire evacuation information that is very important for the safe evacuation of every worker.

\section{Conclusions}

Miners are extremely focused on health and safety concerns with the fact that they need to go further and deeper into the ground for ore deposits. With the increasing popularity of wearable devices such as smartphones and smartwatches that are interconnected through sensors that can monitor environmental hazards, location, movement, heart rate, etc., it is an important progression that this is integrated into PPE to enable improved safety management on the work site. This wearable PPE technology will transform how those in the mining industry manage and view their approach to safety.

The prototype system presented in this paper is characterized by "smart" products that collect data from sensors and then communicate that data to other IoT devices where data can be stored, analysed, shared and acted upon as usable information.

With the exponential growth of smart devices and advanced connectivity, IoT communication can gain traction in many areas of mining that can optimize efficiency and develop new safe work practices. The use of this technology that is accelerating with mobile and cloud 
innovation is becoming more affordable and practical as the price and size of sensors shrink.

Mining companies that accept innovative technologies can be the first to gain an advantage and become far more sustainable and cost competitive in this cyclical industry.

We can categorize some of the possibilities which could be enabled by this prototype system that uses sensors attached to regular PPE clothing that are interconnected with smartphones and smartwatches:

1. Protection from invisible risks - PPE with gas, dust, sound, smoke and temperature sensors can monitor both the external environment and the user, alerting them in time about hazardous environments and alerting supervisors if workers are in unsafe conditions.

2. Locating system - tracking systems that are attached to every smartphone connected to network can enable the identification of the location of each miner.

3. Real-time data analytics - this would enable an immediate alert to a worker if he enters a potentially hazardous zone or somehow risks his safety.

4. Smart communication systems - The interconnected sensors and smartphones could provide fast and effective communication in loud or low-visual environments.

5. Smartphone app alerts - sensors connected to apps can send crucial alerts about emergency situations and also auto send emergency rescue messages.

6. Improve performance and reduce error - smart PPE improves productivity through connectivity, live updates and remote communication that can save lives and actively prevent workplace accidents.

7. Smart health - monitor workers' heart rates and physical work overload.

\section{References}

Amft, O., Lukowicz, P. (2009): From Backpacks to Smartphones: Past, Present, and Future of Wearable Computers. IEEE Pervasive Computing, vol. 8, no. 3, 8-13, doi: 10.1109/MPRV.2009.44.

Atzori, L., Iera, A., Morabito, G. (2010): The Internet of Things: a survey. Computer Networks Volume 54, Issue 15, 2787-2805, doi:10.1016/ jcomnet.2010.05.010.

Barro-Torres, S., Fernandez-Carames, T., Perez-Iglesias, H., Escudero, C. (2012): Real-time personal protective equipment monitoring system. Computer Communications 36, 42-50, doi:10.1016/j.comcom.2012.01.005.

Bertino, E., Nepal, S., Ranjan, R. (2015): Building SensorBased Big Data Cyberinfrastructures. IEEE Cloud Computing, vol. 2, no. 5, 64-69, doi:10.1109/MCC.2015.106.

Bettini, C., Brdiczka, O., Henricksen, K., Indulska, J., Nicklas, D., Ranganathan, A., Riboni, D. (2010): A survey of context modelling and reasoning techniques. Pervasive and Mobile Computing Volume 6, Issue 2, 161-180, https:// doi.org/10.1016/j.pmcj.2009.06.002.
Bhattacharjee, S., Roy, P., Ghosh, S., Misraa, S., Obaidatb, M. (2012): Wireless sensor network-based fire detection, alarming, monitoring and prevention system for bord-andpillar coal mines. Journal of Systems and Software, Volume 85, Issue 3, 571-581, doi:10.1016/j.jss.2011.09.015.

Burchard, B., Jung, S., Ullsperger, A., Hartmann, W.D. (2001): Devices, software, their applications and requirements for wearable electronics. Consumer Electronics, International Conference on Consumer Electronics, Los Angeles, CA, 224-225, doi:10.1109/ICCE.2001.935285.

Edwards, J.C., Friel, G.F., Franks, R.A., Lazzara, C.P., Opferman, J.J. (2000): Mine fire source discrimination using fire sensors and neural network analysis. In: Proceedings of the 2000 Technical Meeting of the Central States Section of the Combustion Institute, 207-211.

Forsyth, J.B., Martin, T.L., Young-Corbett, D., Dorsa, E. (2012): Feasibility of Intelligent Monitoring of Construction Workers for Carbon Monoxide Poisoning. IEEE Transactions on Automation Science and Engineering, vol. 9, no. 3, 505-515, doi: 10.1109/TASE.2012.2197390.

Guidoa, G., Vitalea, A., Astaritaa, V., Saccomannob, V., Giofrea, V.P., Gallellia, V. (2012): Estimation of safety performance measures from smartphone sensors. Procedia - Social and Behavioral Sciences 54, 1095-1103, https://doi. org/10.1016/j.sbspro.2012.09.824.

Hu, S., Tang, C., Yu, R., Liu, F., Wang, X. (2013): Intelligent coal mine monitoring system based on the Internet of Things. 3rd International Conference on Consumer Electronics, Communications and Networks, Xianning, 380384, doi: 10.1109/CECNet.2013.6703350.

Jiang, Y., Li, Z., Yang, G., Zhang, Y., Zhang, X. (2017): Recent progress on smart mining in China: Unmanned electric locomotive. Advances in Mechanical Engineering, Vol. 9(3), 1-10, DOI: 10.1177/1687814017695045.

Makris, P., Skoutas, D. N., Skianis, C. (2013): A Survey on Context-Aware Mobile and Wireless Networking: On Networking and Computing Environments' Integration. IEEE Communications Surveys \& Tutorials, vol. 15, no. 1, 362386, doi:10.1109/SURV.2012.040912.00180.

Miorandi, D., Sicari, S., De, Pellegrini F., Chlamtac, I. (2012): Internet of Things: vision, applications and research challenges. Ad Hoc Networks, Volume 10, Issue 7, 1497-1516, doi:10.1016/j.adhoc.2012.02.016.

Mourcou, Q., Fleury, A., Franco, C., Klopcic, F., Vuillerme, N. (2015): Performance Evaluation of Smartphone Inertial Sensors Measurement for Range of Motion. Sensors 15, 23168-23187, doi:10.3390/s150923168.

Mukhopadhyay, S.C. (2015): Wearable Sensors for Human Activity Monitoring: A Review. IEEE Sensors Journal, vol.15,no.3,1321-1330, doi:10.1109/JSEN.2014.2370945.

Perera, C., Zaslavsky, A., Christen, P., Georgakopoulos, D. (2014): Context Aware Computing for The Internet of Things: A Survey. IEEE Communications Surveys \& Tutorials, vol. 16, no. 1, 414-454, doi: 10.1109/SURV.2013. 042313.00197.

Podgórski, D., Majchrzycka, K., Dąbrowska, A., Gralewicz, G., Okrasa, M. (2017): Towards a conceptual framework of OSH risk management in smart working environments 
based on smart PPE, ambient intelligence and the Internet of Things technologies. International Journal of Occupational Safety and Ergonomics, 23:1, 1-20, DOI: 10.1080 /10803548.2016.1214431.

Qiupinga, W., Shunbinga, Z., Chunquana, D. (2011): Study on key technologies of Internet of Things perceiving mine. Procedia Engineering 26, 2326-2333, doi:10.1016/j.proeng.2011.11.2442.

Rooney, S., Bauer, D., Scotton P. (2006): Techniques for integrating sensors into the enterprise network. IEEE Transactions on Network and Service Management, vol. 3, no. 1, 43-52, doi:10.1109/TNSM.2006.4798306.
Su, X., Tong, H., Ji, P. (2014): Activity recognition with smartphone sensors. Tsinghua Science and Technology, vol. 19, no. 3, 235-249, doi: 10.1109/TST.2014.6838194.

Witt, J., Schukar, M., Krebber, K., Pažoutová, H., Demuth, J., Santostefano, N., Mäkinen, H., Pietrowsk,i P. (2013): Personal protective equipment with integrated POF sensors. Fifth European Workshop on Optical Fibre Sensors, 121132, doi: 10.1117/12.2026831.

Zaslavsky, A., Perera, C., Georgakopoulos, D. (2012): Sensing as a service and big data. International Conference on Advances in Cloud Computing (ACC-2012), Bangalore, India, 21-29.

\section{SAŽETAK}

\section{Arhitektura sustava za praćenje osobne zaštitne opreme i senzora u cilju povećanja sigurnosti rada u podzemnim rudarskim postrojenjima}

Sigurnost na radnome mjestu najvažniji je čimbenik rada u svakoj industrijskoj grani. Stoga su razvijene brojne nove tehnologije i inovacije s ciljem podizanja razine sigurnosti na radnome mjestu, pa tako i u rudnicima, na gradilištima, u elektranama, tvornicama itd. Postavljanje senzora u osobnu zaštitnu opremu omogućuje praćenje raznih varijabli poput tjelesnih funkcija, izloženosti opasnim tvarima, udaljenosti od rizičnih područja te drugih. Takva tehnologija može se povezati s pametnim telefonima ili ekranima te radnicima omogućiti veću sigurnost i praćenje sigurnosnih varijabli na mjestima gdje rade. Prikazan je jedan takav sustav, prototip, koji se može primijeniti u rudarstvu. Senzori toga sustava dodani su na uobičajenu zaštitnu odjeću, kacigu ili naočale te povezani s pametnim telefonom Bluetooth vezom. Oni u stvarnome vremenu omogućuju praćenje sigurnosti radnoga okoliša te reakciju na potencijalno opasnu situaciju.

\section{Ključne riječi:}

podzemna eksploatacija, osobna zaštitna oprema, internet stvari, senzori, sigurnost na radu

\section{Author(s) contribution}

This paper is part of a scientific project with the title "Application of computer apps and technologies for improving the effectiveness and safety at work in underground mines." Vancho Adjiski (Assistant Professor) initialised an idea on the topic of the paper, wrote the paper and prepared the graphics. Zoran Despodov (Full Professor) and Dejan Mirakovski (Full Professor) technically improved and supervised the work. Dalibor Serafimovski (Assistant Professor) provided guidelines for the methodology for system integration and PPT assembly. 